\title{
The Design of Automatic Control System for Friction Plate Forming Equipment
}

\author{
Yuesheng Wang ${ }^{1, a}$, Dawei Zheng ${ }^{2, b}$ \\ ${ }^{1}$ Hangzhou Dianzi University, Hangzhou 310018, China; \\ ${ }^{2}$ Hangzhou Dianzi University, Hangzhou 310018, China. \\ awys@hdu.edu.cn, bsuccessstep@163.com
}

Keywords: Friction plate, Touch screen, PLC, Servo system

\begin{abstract}
Due to the special requirements of the clutch friction plate production, the previous manual operation has been unable to meet the actual production requirements. This paper designs a control system for friction plate forming equipment aiming at different types of automobile clutches, by using the PLC and servo system technology, fusing the touch screen control technology. The system uses PLC digital pulse signal to control the servo system, and realizes the position control of the object. The system can realize substitution machine, improving the yield and the quality of the products and bring significant economic benefits for enterprises.
\end{abstract}

\section{Introduction}

Automobile clutch friction plate is an important part of motor vehicles, and is also the main component of friction clutch. Friction winding molding equipment is basically belongs to the pure mechanical machine and manual adjustment of the special machine. There are some problems in the production of the product, such as the quality is not stable, the poor performance is poor, the production rate is low. A worker only can operate a winding molding equipment at one time ${ }^{[1]}$. In addition, imported equipment was expensive. At present, many domestic enterprises use purely mechanical and manual adjustment machine tools. The problems in the production need to be solved urgently. Combined with the practice, this paper designs a set of machine - electricity - gas - control integration of the friction disk of automobile clutch automatic winding equipment, which can not only realize "replacing people with machines" and improve the degree of automation in production, reduce labor intensity, one person can operate more than two sets of production equipment. Friction plate automatic winding molding equipment will bring huge economic benefits for the users and enterprises.

\section{System overall scheme design}

\subsection{System working principle}

Automobile clutch friction plate automatic winding machine tool uses PLC and touch screen as the control level $^{[2]}$. The touch screen displays system status information, generates switch information. The operator can enter the value and character to preset the PLC. After the PLC has been set up, the digital signal is sent to the AC servo drive control device, which controls the AC servo motor to coordinate the work ${ }^{[3]}$. AC servo motor controls the line material and rotating winding plate, and at the end of winding outputs forming friction plate.

\subsection{System structure}

The system is composed of 3 layers, the first layer is the touch screen and the man-machine interface, the information display and the man-machine interaction. The second layer is the control system layer, including PLC system, AC servo drive control device and AC servo motor. The third layer is the controlled object layer. The overall architecture and hierarchy of the system is shown in figure 1. 


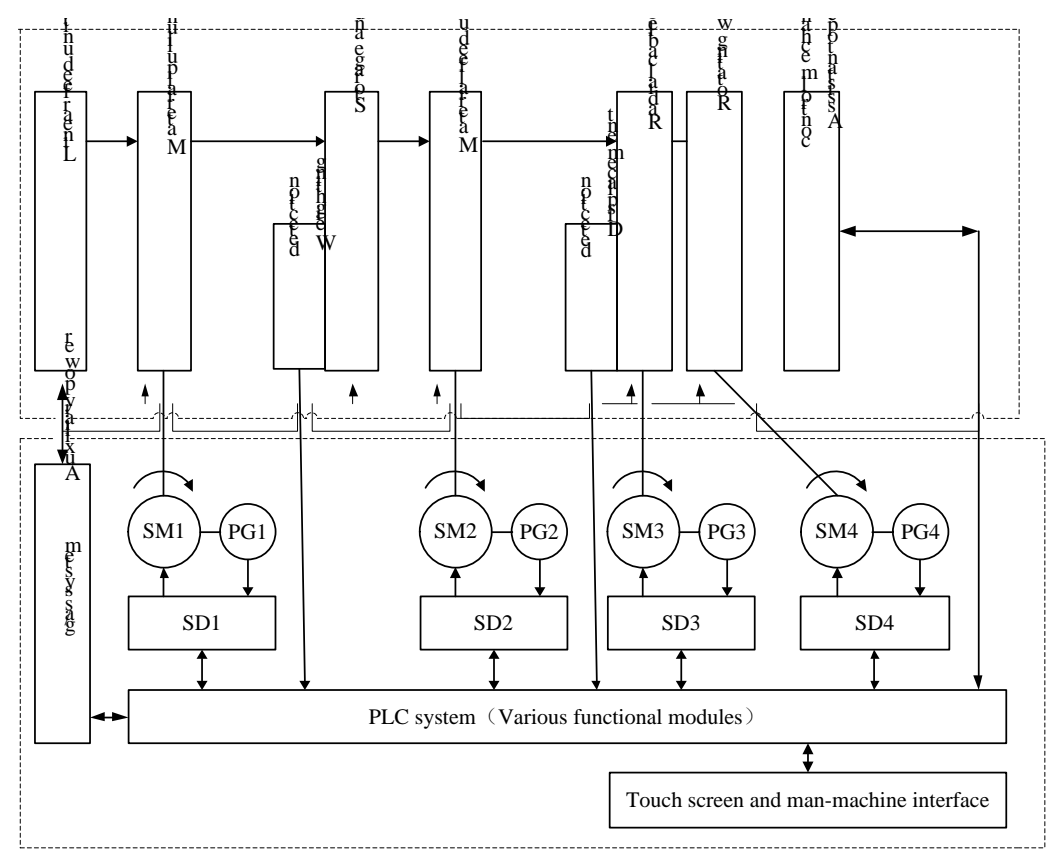

Fig.1 System overall architecture diagram

\section{System hardware design}

The control system of friction plate molding equipment consists of the touch screen, PLC, driver, servo motors and other modules, the block diagram of system hardware module shown in figure 2 . A digital AC servo system is used and through the position instruction pulse issued by upper controller, the function of position control is realized ${ }^{[4]}$.

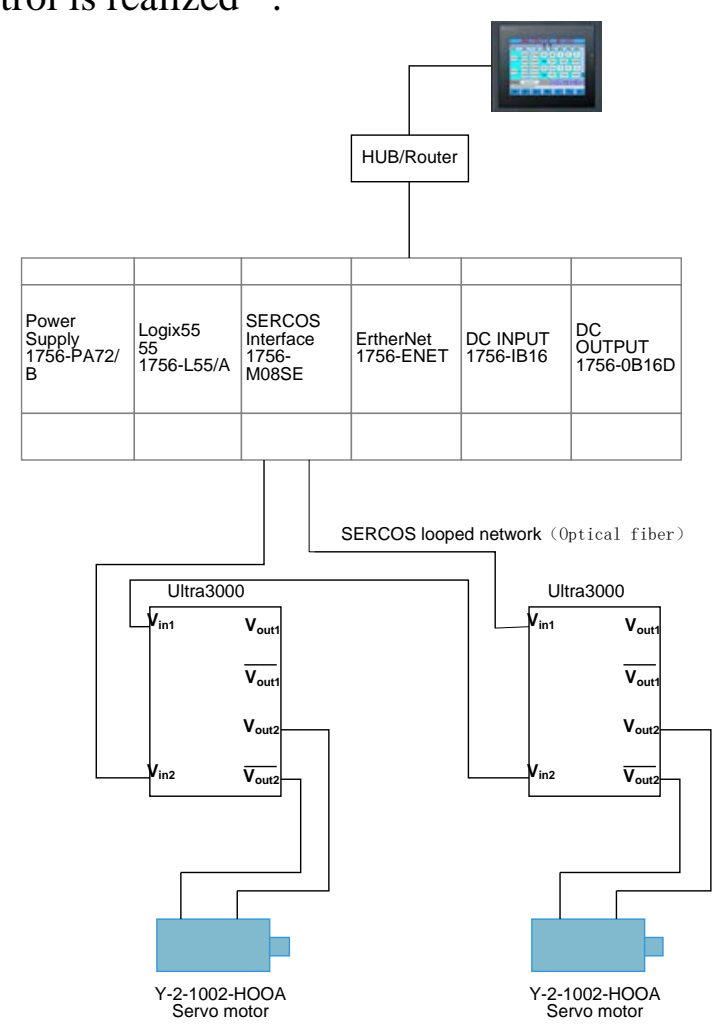

Fig.2 Block diagram of hardware

\subsection{System working principle}

When the system works, the PLC is controlled by the frequency of the pulse signal to control the servo drive, and the servo driver sends the command to control the servo motor ${ }^{[5]}$. In addition, we add encoder for closed loop control of servo motor to ensure the accuracy of the system. 


\subsection{Driver and servo motors module design}

The system uses Delta ASDA servo driver, this series supports 17-bit (160,000 p / rev) high resolution encoder and meets the application requirements of high-precision positioning control and smooth low-speed operation of equipment. Driver is put inside three modes, that is position mode, speed mode and torque mode. Under the position mode, the electrical gear ratio is N/M and the limited conditions is $(1 / 50<\mathrm{N} / \mathrm{M}<25600)$. The communication interface of server supports $\mathrm{RS}-232$ and RS-485.

\section{System software design}

\subsection{Touch-screen interface design}

The programming software of MT506 touch screen is used to achieve the development of interactive interface, by using the graphical programming method, simply drag the related components to the pre-defined screen and rationally configure the write address of PLC to complete the operation according to the parameters to be set ${ }^{[6]}$. Firstly use RS232 serial port of the touch screen to download the designed interactive interface to the touch screen, and then use this serial port to communicate with the PLC.

\subsection{System software framework design}

The control system of friction plate molding equipment uses the software STEP 7-Micro/WIN 32 to program and mainly adopts the methods of ladder programming. In the software design, the MAJ and the MAS instruction are used to compile the manual program. In the program, the MAJ instruction is used for the pointing servo axis. The MAS instruction or another MAS instruction can be used to stop the axis which is in the course of pointing movement. According to the information on the screen input by the operator, the PLC system chooses different control variables to control the servo motor ${ }^{[7]}$. The software design of control system of friction plate molding equipment constructs around the system operating mode, which can be divided into three ways, namely automatic mode, manual mode and no material mode. The software block diagram of control system is shown in Figure 3.

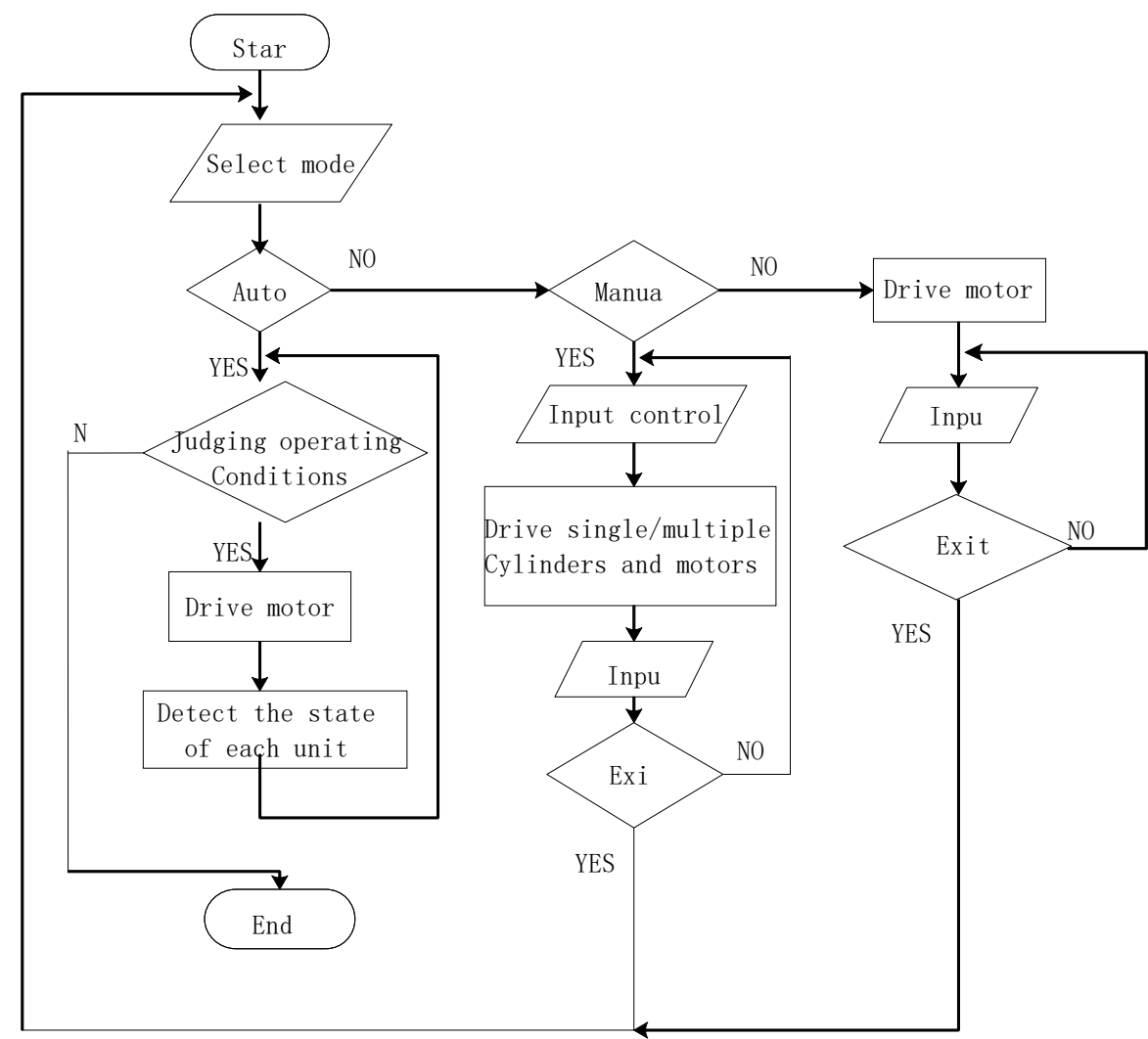

Fig.3 Software block diagram of the control system of the friction sheet forming equipment 


\section{Summary}

The design of the control system of friction plate molding equipment is based on PLC and servo system control technology, the digital pulse signal generated by PLC is used as the input control signal of servo system to control the servo motor, and the system also has good interactive capability. The design gives a new optimization solution for the existing problems, such as low productivity and poor consistency of manual winding production. This design not only can effectively reduce the labor intensity, but also can double the production, increase the efficiency and significantly improve product quality and consistency of the friction plate.

\section{References}

[1] .Gao Huihui.Study on the friction and wear properties of micro car clutch and its mechanism [D]. Wuhan: Wuhan University of Technology, 2008;

[2]. Qi Fenglian, Chen Xiaonan, Zhao Min, Xu Lijuan, Lei Dongliang. Based on touch screen and PLC automatic boring and milling machine control system [J]. Manufacturing technology and machine tool, 2012, No. 6;

[3] Tao Kerui, Zhu Lianqing. PLC control servo motor application design [J]. Chinese high-tech enterprises, 2009, thirteenth

[4] Zhang Zhi. PLC servo motor and touch screen in the control system of [J]. packaging and food machinery, 2007, twenty-fifth volume fifth;

[5] Huang Jianxin, Liu Jianqun, Kuang Hui, Wu Shilin. Touch screen and PLC composition of servo motor control system [J]. Instrument technique and sensor, 2005, issue 2;

[6] Zhang Shixiong. Research on high performance AC servo drive control technology for CNC machine tools [D]. Guangzhou: South China University of Technology, 2010;

[7] Liu Yan. Touch screen and PLC communication with [J]. automation and instrumentation, fourth, 2002 